


\title{
Oats (Avena sativa) reduce atherogenesis in
}

\section{LDL-receptor deficient mice.}

\author{
Andersson $\mathrm{KE}^{1}$, Svedberg $\mathrm{KA}^{1}$, Lindholm $\mathrm{MW}^{2}$, Öste $\mathrm{R}^{3}$, Hellstrand $\mathrm{P}^{1}$ \\ ${ }^{1}$ Department of Experimental Medical Science, ${ }^{2}$ Department of Clinical Sciences, \\ ${ }^{3}$ Department of Food Technology, Engineering and Nutrition, Lund University, Sweden
}

Supplementary material: Expanded Material and Methods, 2 tables

Correspondence and proofs to:

Dr. Per Hellstrand

Vascular Physiology Group

Department of Experimental Medical Science,

Lund University

BMC D12,

SE-221 84 Lund, Sweden

Phone: +46-46-2229585

Fax: $\quad+46-46-2113417$

E-mail: Per.Hellstrand@med.lu.se 


\section{ABSTRACT}

Aim: The cholesterol-lowering properties of oats, largely ascribed to its contents of soluble fibers, beta-glucans, are well established, whereas effects on atherogenesis are less well elucidated. Oats also contains components with reported antioxidant and antiinflammatory effects that may affect atherogenesis. In this work we examined effects of oat bran on plasma cholesterol, markers of inflammation, eNOS expression and development of atherosclerosis in LDL-receptor-deficient $\left(\mathrm{LDLr}^{-/}\right)$mice.

Methods and results: Female $\mathrm{LDLr}^{-/-}$mice were fed Western diet \pm oat bran. Two concentrations of oat bran (40 and 27\%) were compared regarding effects on plasma lipids. There was a dose-dependent reduction of plasma cholesterol by 42 and $20 \%$ with 40 and 27 $\%$ oat bran, respectively. Both concentrations also lowered plasma triglycerides (by 45 and 33 $\%)$ and relative levels of plasma LDL+VLDL. The reduction of plasma lipids was accompanied by increased faecal excretion of cholesterol and bile acids. Oat bran (40\%) efficiently reduced atherosclerotic lesion area in the descending aorta $(-77 \%)$ and aortic root (33\%). Plasma levels of fibrinogen and soluble vascular cell adhesion molecule-1 (VCAM-1) were significantly lower, and immunofluorescence of aortic sections revealed a $75 \%$ lower expression of VCAM-1 in oat-fed mice. The expression of eNOS protein in the aortic wall was increased in mice fed oat bran.

Conclusions. Oat bran supplemented to a Western diet lowers plasma cholesterol, reduces levels of some inflammatory markers, increases eNOS expression and inhibits atherosclerotic lesion development in $\mathrm{LDLr}^{-/-}$mice. It remains to be investigated which components in oats contribute to these effects. 


\section{1. Introduction}

2 Atherosclerosis is a chronic inflammatory process involving immunomodulatory compounds,

3 immune cells and blood lipids[1]. Elevated plasma concentrations of total or low density

4 lipoprotein (LDL) cholesterol are powerful risk factors for atherosclerosis, while high concentrations of high density lipoprotein (HDL) cholesterol or a low LDL / HDL ratio are considered to protect against vascular disease. Atherosclerosis is expected to be associated with increased levels of inflammatory markers, present in the lesions as well as in blood plasma[2]. Moreover, endothelial dysfunction, with reduced NO production, has emerged as an important underlying factor in the pathogenesis of vascular disease. Nutritional factors are connected with the development of atherosclerosis, and efforts to reduce the rapidly spreading

11 adverse effects associated with Western eating habits are highly needed[3].

During the last decades the role of dietary fibers in the control of lipid and lipoprotein metabolism has attracted much attention. Oats and soluble fibers from oats, beta-glucans, have been shown to reduce plasma cholesterol levels in man[4-6]. In vitro experiments point in the direction that also other components in oats, such as vitamin E ( $\alpha$-tocopherol), phenolic acids, flavonoids and sterols may have antiatherosclerotic properties by exerting antioxidative and anti-inflammatory effects, and by retaining endothelial function[7-9]. This suggests that increased consumption of oat-based food products may be beneficial in reducing the incidence and severity of atherosclerosis in the general population. More knowledge is however needed, including evaluation of which properties of oats are crucial for reducing atherosclerosis, as this would allow the development of optimal oat-based food components. Animal studies will be helpful for this purpose, and despite extensive studies of the lipidlowering properties of oat products[4-6] there are few investigations directly addressing atherosclerosis development. The effects of several fiber products, including oat bran, on lipid infiltration in aortas of Syrian hamsters fed a cholesterol-enriched diet have been studied in 
1 relation to effects on plasma lipids[10,11], but inflammatory markers or endothelial functions

2 were not investigated. Mice are advantageous in comparison with other animal experimental

3 models, in view of the large number of genetic variants and extensive information on

4 atherogenic mechanisms available in this species. We have shown that oat bran reduces total

5 and LDL/HDL ratio in C57BL/6 mice[12]. For the study of atherosclerosis, mouse models

6 with propensity for hyperlipidemia offer the possibility to study lesion development over

7 limited time periods.

8 The most common lipoprotein pattern in humans with coronary artery disease consists of

9 elevated plasma levels of LDL with or without increases in VLDL, and decreased

$10 \mathrm{HDL} /(\mathrm{LDL}+\mathrm{VLDL})$ ratio[1]. Such a lipoprotein pattern is seen in LDL-receptor knock-out

$11\left(\mathrm{LDLr}^{-/}\right)$mice, which develop atherosclerotic lesions when fed a high-fat ("Western") diet

12 [13]. The present study aimed to investigate the effects of oats on atherosclerotic lesion

13 formation, markers of inflammation, endothelial function and plasma lipids in LDLr ${ }^{-/-}$mice.

14 Oat bran was used here to establish effects of unprocessed oats. In addition to the mechanistic

15 information obtained, the results will be useful as a reference for further studies involving

16 isolated oat components.

\section{Materials and methods}

\subsection{Mice}

Female LDL-receptor-deficient homozygous $\left(\mathrm{LDLr}^{-/}\right)$mice were purchased from Charles

21 River Laboratories (Sulzfeld, Germany). All experiments were approved by the Malmö/Lund regional ethical committee for laboratory animals (M86-05) and followed national guidelines for the care and use of animals. At 8-10 weeks of age, the mice were randomly divided into two groups of 20 animals. One group was fed Western diet supplemented with $40 \%$ oat bran 
1 and the other group control Western diet for 16 weeks. In a separate, 4-week, follow-up experiment we evaluated the effects on plasma cholesterol of a lower concentration of $27 \%$ oat bran, and the expression of eNOS in the aortic arch.

\subsection{Diets}

A Western diet (Research Diets Inc., NJ, USA) was supplemented with $40 \%$ or $27 \%$ oat bran (wt/wt) at the expense of casein, corn starch, sucrose and butter (please see online Tables S1 and S2). Control and oat bran diets were formulated to keep fiber contents, energy and macronutrients equal, with $16 \%$ protein, $42 \%$ carbohydrates, $42 \%$ fat (energy percent) and $0.05 \%$ cholesterol in both control and oat bran diets. In the control diets oat fibers were replaced by microcrystalline cellulose, see[12] for details. Feed consumption was determined per cage over 1-week periods and expressed as gram consumed per mouse per day.

\subsection{Tissue sampling and analyses}

Blood samples drawn from vena saphena at baseline and at weeks 1, 2, 4, 8, 12 and 16 were collected after $4 \mathrm{~h}$ fasting. At week 16 all the faeces excreted during $24 \mathrm{~h}$ were collected from each cage (10 mice/cage). At the end of the study mice were anaesthetized and perfusion fixed. The aorta was mounted en face and stained with Oil Red O. Lesion areas were quantitated using Image ProPlus 4.5 Software (MediaCybernetics, Inc. MD, USA). Cryo sections of the aortic root were used for immunofluorescence detection of VCAM-1 and for lesion analysis with Oil Red $\mathrm{O}$ and hematoxylin staining, respectively. The caecum with its contents was removed, emptied and weighed. For analysis of eNOS by Western blot, mice were sacrificed by cervical dislocation and the aorta dissected free and frozen at $-80^{\circ} \mathrm{C}$.

\subsection{Plasma analyses}

Total plasma cholesterol and triglyceride levels were determined enzymatically. Plasma lipoproteins were separated by electrophoresis in $0.8 \%$ agarose gels in barbital buffer as 
1 described previously [12]. The relative lipid distribution between HDL and VLDL+LDL was

2 calculated. This method does not reveal LDL cholesterol directly, but rather shows the

3 distribution of total lipids (cholesterol, triglycerides and phospholipids) among the different

4 lipoproteins. Commercially available murine ELISA kits were used for measuring plasma

5 levels of inflammatory markers serum amyloid A (SAA), fibrinogen, interleukin-6 (IL-6) and

6 soluble VCAM-1 (sVCAM-1) in plasma.

7

8

9

\subsection{Immunofluorescence}

Cryo sections of the aortic root were incubated with primary rat-anti-mouse VCAM-1 antibodies (Chemicon) and then with secondary Cy5 donkey-anti-rat antibodies (Santa Cruz). Nuclei were counter-stained with SYTOX ${ }^{\circledR}$ Green (Molecular Probes, (Invitrogen) USA). A Zeiss LSM 5 Pascal laser scanning confocal microscope was used to quantitate the VCAM-1 stained area relative to the total vessel wall area.

\subsection{Western blot}

Proteins were separated with SDS-PAGE (10.5-14\% gels) and transferred to a nitrocellulose membrane. The membranes were incubated with an antibody against eNOS (BD Transduction Lab.), detected with chemiluminescence (West Femto, Nordic Biolab) and analyzed with Quantity One software (BioRad). Intensities of eNOS-bands were normalized to corresponding parts of the gel stained with Comassie Blue following transfer as loading control.

\subsection{Statistical analysis}

Data are expressed as mean \pm SEM if not otherwise stated. Differences between oat bran and control were compared by Student's t-test for unpaired data, while paired t-tests were used for within-group changes from baseline. In lesion analysis of flat preparations data 
1 median values were analyzed with Mann-Whitney U-test. Values of $\mathrm{P}<0.05$ were considered

2 statistically significant.

3 An extended section 2 is presented as Supplementary data.

\section{Results}

\subsection{Body weight and feed intake}

There was no difference in feed intake between oat bran groups and control groups, and all groups of mice gained body weight throughout the study, with a somewhat greater increase in

9 the oat bran than in the control group (Table 1). Greater weight gain in oat-fed animals has

10 earlier been observed in rats[14].

\subsection{Oat bran reduces plasma lipids in $L D L r^{-/-}$mice.}

Western diet induced a prominent increase in plasma cholesterol. Cholesterol levels of mice fed $40 \%$ oat bran were approximately $40 \%$ lower than those of controls throughout the study (Fig. 1A). Oat bran (27\%) led to a reduction of plasma cholesterol by $20 \%$ (Fig. 1B). Plasma triglycerides were more than doubled when mice were fed the Western diet, but were reduced by $45 \%$ and $33 \%$ by 40 and $27 \%$ oat bran, respectively (Fig. 1C).

Although the Western diet greatly increased total cholesterol, there were no dramatic changes in lipoprotein profiles in the $\mathrm{LDLr}^{-/-}$mice. In control groups the relative LDL+VLDL lipid levels were higher at the end of the studies (16 and 4 weeks) compared to baseline, whereas there were no statistically significant differences from baseline in the oat bran groups. At the end of the studies the relative amounts of LDL+VLDL lipids were significantly lower in the oat-fed mice (both with $40 \%$ and $27 \%$ oat bran) than in controls (Fig. 1D). 


\subsection{Cholesterol and bile acid excretion and caecum contents}

There was an almost fourfold increase in faecal cholesterol excretion (Fig. 1D) and a 40\% increase in faecal bile acid excretion (Fig. 1E) in mice fed oat bran (40\%), although the total amount of faeces excreted did not differ: 2.47 and $2.51 \mathrm{~g} / \mathrm{mouse} / 24 \mathrm{~h}$ in control and oat-fed mice, respectively. The mice fed $40 \%$ oat bran had almost twice as much caecum contents as the control mice and also had higher caecum wall wet weights. The lower concentration of oat bran $(27 \%)$ did however not cause any statistically significant changes in either caecum content or caecum wall weight (Table 1).

\subsection{Effects of oat bran on inflammation markers}

The acute-phase proteins fibrinogen and serum amyloid A (SAA) as well as IL-6 and sVCAM-1 were analyzed in plasma samples after 16 weeks on experimental diet. Fibrinogen was significantly lower in mice fed oat bran $(40 \%)$ than in control mice $(\mathrm{P}<0.001$; Fig. $2 \mathrm{~A})$, whereas SAA tended to be lower but no significant difference was found ( $\mathrm{P}=0.09$; Fig. $2 \mathrm{~B})$. Oat bran (40\%) did not alter plasma concentrations of IL-6 (Fig. 1C). The sVCAM-1 concentration was reduced by $10 \%$ and $7 \%$ in mice fed 40 and $27 \%$ oat bran, respectively $(\mathrm{P}<0.05$; Fig. 2D and E). Confocal immunofluorescence analysis of cryosections of the aortic root revealed that oat bran (40\%) significantly reduced the expression of the adhesion molecule VCAM-1 in the vessel wall (Fig. 3A and B).

\subsection{Effect of $27 \%$ oat bran on eNOS expression}

The eNOS expression in the aorta was determined after 4 weeks on an experimental diet containing $27 \%$ oat bran or control fiber. Western blot analysis of the aortic arch revealed a greater eNOS expression in mice fed oat bran (Fig. 3C). 


\subsection{Oat bran reduces atherosclerotic lesion development.}

The effect of oats on atherosclerosis was evaluated in en face preparations of the descending aorta, and in cryosections of the aortic root, stained by Oil Red O (Fig. 4A andB). Oat bran (40\%) diet significantly reduced lipid infiltration in the descending aorta, with median value for lesion area of $0.19 \%$ of total aortic area vs. $0.82 \%$ in control mice (Fig. $4 \mathrm{~A})$.

The control and oat-fed groups each contained three outliers with elevated lesion areas, whereof one in the oat group had an excessively large lesion area. These outliers did not differ from the rest of the mice in any other investigated respect and were all included in the results and statistical analysis. The total lesion area in the aortic root was also significantly smaller in mice fed oat bran (40\%) (Fig. 4B).

\section{Discussion}

Effects of two doses of oat bran were evaluated in this work. We started with a high (40\%) dose to ascertain an effect on plasma lipids and on atherosclerosis to establish the model. A lower dose $(27 \%)$ was then used in a shorter follow-up study with plasma lipids as main endpoint. Results suggest that oat bran causes a dose-dependent reduction of plasma cholesterol in $\mathrm{LDLr}^{-/-}$mice. Oat bran also reduces atherosclerotic plaque development and some inflammatory markers, and furthermore increases bile acid excretion and the expression of eNOS in the aortic wall of LDLr ${ }^{-/-}$mice. The study extends our recently reported observations on plasma lipids in $\mathrm{C} 57 \mathrm{BL} / 6$ mice[12] by directly demonstrating antiatherogenic effects of oats in a hyperlipidemic mouse model.

A smaller atherosclerotic lesion area after 16 weeks of Western diet was found in the oatfed mice relative to the control group. Reduced levels of plasma cholesterol in the oat-fed mice are probably the most important reason for the reduced atherosclerotic lesion area. 
1 However, oat bran contains components that may exert antioxidative and anti-inflammatory

2 effects, such as vitamin E ( $\alpha$-tocopherol), phenolic acids, flavonoids and sterols[7]. The

3 summed effect of these compounds could possibly counteract atherosclerotic lesion

4 development in addition to the effect of lowered plasma lipids.

5 Atherosclerosis is a disorder driven by inflammation, and the molecular mediators of inflammation also serve as inflammatory markers to predict future cardiovascular risk[2].

7 Examples of such markers include the plasma acute-phase proteins C-reactive protein (CRP),

8 SAA and fibrinogen, as well as cytokines such as IL-6, IL-1 and TNF $\alpha[15]$. In LDLr ${ }^{-/-}$mice

9 fed high-fat diet the prevalence of atherosclerotic lesions correlates with increased plasma

10 concentrations of SAA[16], and elevated levels of the adhesion molecules VCAM-1 and

11 ICAM-1 on endothelial and vascular smooth muscle cells have been found in atherosclerosis[17]. Dietary factors can influence systemic inflammation. For example, human consumption of whole grains has been shown to correlate with reduced CRP levels as well as with reduced progression of coronary atherosclerosis[18,19], and reduction of adhesion molecule expression by flaxseed dietary fibers was associated with reduced atherosclerosis in $\mathrm{LDLr}^{-/-}$mice on a high-fat $\operatorname{diet}[17]$. Regarding oats, very little in vivo evidence on anti-inflammatory effects exists. In a recent human study, consumption of oat beta-glucans was shown to effectively reduce LDL cholesterol but no influence on 19 inflammatory markers could be demonstrated[20,21].

In the present in vivo study, plasma markers of inflammation (sVCAM-1 and fibrinogen), 21 as well as the expression of VCAM-1 in lesion areas, were reduced in the oat-fed mice. There was also a tendency to reduced levels of plasma SAA. We did not see an effect on plasma levels of IL-6, but cannot exclude that different results would have been obtained at other

24 time points. Possibly, plasma levels of cytokines and other inflammatory markers are more 25 affected postprandially than in a fasted state as studied here. Avenanthramides, oat-specific 
1 phenolic antioxidants, have been shown to reduce levels of VCAM-1, ICAM-1 and IL-6 in

2 endothelial cells in vitro[8], and other antioxidants (vitamin E, vitamin C and beta-carotene)

3 have been shown to reduce levels of sVCAM-1 in wild-type and ApoE*3 Leiden mice[22].

4 Therefore avenanthramides, E-vitamins and other phenolic compounds present in oat bran,

5 although in low concentrations, may have contributed to an anti-inflammatory effect. We can

6 however not rule out that the reduced levels of blood lipids in the oat-fed mice was an

7 important factor for the reduced inflammation observed, since hyperlipidemia per se elicits

8 pro-inflammatory responses[23].

9 Generation of nitric oxide (NO) by endothelial nitric oxide synthase (eNOS) is known to

10 protect against vascular disease, and eNOS/ApoE double knockout mice on a high-fat diet

11 show accelerated atherosclerosis[24]. In vitro studies have shown that polyphenols from oats can increase the expression of eNOS in endothelial cells[9]. In the present in vivo study, we

13 found increased eNOS protein levels in the aortic arch of oat-fed mice compared with controls. This suggests that oats are indeed able to improve endothelial function. Previous studies in $\mathrm{LDLr}^{-/-}$mice have indicated that reduction of inflammation by antioxidants can 16 limit atherosclerosis and increase NO production at constant plasma lipid levels[25]. Further studies are needed to address this issue for oats, with its inherent effects on plasma lipids. Possible approaches would involve either modification of diets to produce similar lipoprotein levels in the absence and presence of oats, or extraction of constituents with presumed antiinflammatory properties from the oat preparation.

21 One of the postulated mechanisms for the cholesterol-lowering effect of oats is that the beta-glucans either bind bile acids or create a viscous layer at the absorption surface in the small intestine and thereby decrease intestinal uptake of dietary cholesterol and reabsorption of bile acids[26,27]. Accordingly, we observed increases in faecal excretion of both cholesterol and bile acids after oat consumption, as has been found previously in C57BL/6 
1 mice[12], hamsters[11] and humans[28,29]. The increase in bowel contents seen after oat

2 feeding has been attributed to greater water binding and is thought to contribute to the altered

3 viscosity of the intestinal contents[26]. Findings in the $\mathrm{LDLr}^{-/-}$mice are thus consistent with

4 mechanisms thought to account for the effects of oats in the intestinal lumen, although their

5 lack of LDL-receptors reduces cholesterol clearance from plasma.

$\mathrm{The} \mathrm{LDLr}^{-/-}$mice responded to Western diet with a prominent increase of plasma triglycerides, which was significantly reduced by oat bran. Increased serum triglyceride levels are related to atherosclerosis independently of serum levels of HDL and LDL and the triglyceride-rich remnant lipoproteins produced by hydrolysis of VLDL and chylomicrons are highly atherogenic[30]. Correct function of the LDL-receptor is essential for the clearance of

11 lipoprotein remnants although other types of lipoprotein receptors, such as the LDLr related protein (LRP), have been suggested to participate[31]. Therefore, effects of intestinal triglyceride uptake on plasma levels are expected to be amplified in the $\mathrm{LDLr}^{-/-}$mouse. Accordingly, the present results suggest that intestinal triglyceride uptake is reduced by the oat bran diet.

The results of this study in $\mathrm{LDLr}^{-/-}$mice show that oat bran reduces plasma levels of total cholesterol, triglycerides, LDL+VLDL lipoproteins, and some important inflammation markers. It also reduces adhesion molecule expression and increases eNOS expression in the aortic wall. Most importantly, oat bran not only reduces plasma cholesterol, but also inhibits atherogenesis. A limitation with the present study is that the use of whole oat bran does not

21 allow us to see if the reduced atherogenesis and inflammation represent direct effects of 22 components present in oats or if they result entirely from the lowered plasma cholesterol per se. This has to be addressed in future work, where the mouse model will be an important tool. Development of new oat-based products and evaluation of their effects on atherogenesis is 
1 expected to lead to improved public health by providing new approaches to health-beneficial 2 dietary habits.

\section{Acknowledgements}

5 Supported by Functional Food Science Centre (FFSC) at Lund University, the Swedish

6 Research Council (64X-28) and the Heart-Lung Foundation. We thank Tina Immerstrand for

7 analysis of the beta-glucan content of the oat bran and for design and production of the

8 experimental diets. We also thank Ingrid Söderberg for advice and assistance regarding en

9 face aortic preparations and Ina Nordström for lipoprotein and Western blot analyses. 


\section{References}

[1] Lusis AJ. Atherosclerosis. Nature 2000;407:233-241.

[2] Libby P, Ridker PM, Hansson GK. Inflammation in atherosclerosis: from pathophysiology to practice. J Am Coll Cardiol 2009;54:2129-2138.

[3] Getz GS, Reardon CA. Nutrition and cardiovascular disease. Arterioscler Thromb Vasc Biol 2007;27:2499-2506.

[4] Kerckhoffs DA, Brouns F, Hornstra G, Mensink RP. Effects on the human serum lipoprotein profile of beta-glucan, soy protein and isoflavones, plant sterols and stanols, garlic and tocotrienols. J Nutr 2002;132:2494-2505.

[5] Brennan CS, Cleary LJ. Review: the potential use of cereal $(1 / 3,1 / 4)-\beta$-D-glucans as functional food ingredients. J Cereal Sci 2005;42:1-13.

[6] Kelly SA, Summerbell CD, Brynes A, Whittaker V, Frost G. Wholegrain cereals for coronary heart disease. Cochrane Database Syst Rev 2007: CD005051.

[7] Peterson D. Oat Antioxidants. J Cereal Sci 2001;33:115-129.

[8] Liu L, Zubik L, Collins FW, Marko M, Meydani M. The antiatherogenic potential of oat phenolic compounds. Atherosclerosis 2004;175:39-49.

[9] Nie L, Wise ML, Peterson DM, Meydani M. Avenanthramide, a polyphenol from oats, inhibits vascular smooth muscle cell proliferation and enhances nitric oxide production. Atherosclerosis 2006;186:260-266.

[10] Wilson TA, Idreis HM, Taylor CM, Nicolosi RJ. Whole fat rice bran reduces the development of early aortic atherosclerosis in hypercholesterolemic hamsters compared with wheat bran. Nutr Res 2002;22:1319-1322.

[11] Delaney B, Nicolosi RJ, Wilson TA, Carlson T, Frazer S, Zheng GH, et al. Betaglucan fractions from barley and oats are similarly antiatherogenic in hypercholesterolemic Syrian golden hamsters. J Nutr 2003;133:468-475.

[12] Andersson KE, Immerstrand T, Sward K, Bergenstahl B, Lindholm MW, Oste R, Hellstrand P. Effects of oats on plasma cholesterol and lipoproteins in C57BL/6 mice are substrain specific. Br J Nutr 2001;103:513-521.

[13] Lichtman AH, Clinton SK, Iiyama K, Connelly PW, Libby P, Cybulsky MI. Hyperlipidemia and atherosclerotic lesion development in LDL receptor-deficient mice fed defined semipurified diets with and without cholate. Arterioscler Thromb Vasc Biol 1999;19:1938-1944. 
[14] Malkki Y, Torronen R, Pelkonen K, Myllymaki O, Hanninen O, Syrjanen K. Effects of oat-bran concentrate on rat serum lipids and liver fat infiltration. Br J Nutr 1993;70:767-776.

[15] Chait A HY, Oram JF, Heinecke JW. Lipoprotein-associated inflammatory proteins: markers or mediators of cardiovascular disease? J Lipid Res 2005;46:389-403.

[16] Lewis KE, Kirk EA., McDonald TO, Wang S, Wight TN, O'Brien KD, Chait A. Increase in serum amyloid a evoked by dietary cholesterol is associated with increased atherosclerosis in mice. Circulation 2004;110:540-545.

[17] Dupasquier CM, Dibrov E, Kneesh AL, Cheung PK, Lee KG, Alexander HK, Yeganeh BK, Moghadasian MH, Pierce GN. Dietary flaxseed inhibits atherosclerosis in the LDL receptor-deficient mouse in part through antiproliferative and antiinflammatory actions. Am J Physiol Heart Circ Physiol 2007;293:H2394-2402.

[18] Lopez-Garcia E, Schulze MB, Fung TT, Meigs JB, Rifai N, Manson JE, Hu FB. Major dietary patterns are related to plasma concentrations of markers of inflammation and endothelial dysfunction. Am J Clin Nutr 2004;80:1029-1035.

[19] Erkkila AT, Herrington DM, Mozaffarian D, Lichtenstein AH. Cereal fiber and wholegrain intake are associated with reduced progression of coronary-artery atherosclerosis in postmenopausal women with coronary artery disease. Am Heart J 2005;150:94-101.

[20] Theuwissen E, Mensink RP. Simultaneous intake of beta-glucan and plant stanol esters affects lipid metabolism in slightly hypercholesterolemic subjects. J Nutr $2007 ; 137: 583-588$

[21] Theuwissen E, Plat J, Mensink RP. Consumption of oat beta-glucan with or without plant stanols did not influence inflammatory markers in hypercholesterolemic subjects. Mol Nutr Food Res 2009;53:370-376.

[22] Murphy N, Grimsditch DC, Vidgeon-Hart M, Groot PH, Overend P, Benson GM, Graham A. Dietary antioxidants decrease serum soluble adhesion molecule (sVCAM1, sICAM-1) but not chemokine (JE/MCP-1, KC) concentrations, and reduce atherosclerosis in C57BL but not apoE*3 Leiden mice fed an atherogenic diet. Dis Markers 2005;21:181-190.

[23] Libby P, Ridker PM, Maseri A. Inflammation and atherosclerosis. Circulation 2002;105:1135-1143.

[24] Kuhlencordt PJ, Gyurko R, Han F, Scherrer-Crosbie M, Aretz TH, Hajjar R, Picard MH, Huang PL. Accelerated atherosclerosis, aortic aneurysm formation, and ischemic 
heart disease in apolipoprotein E/endothelial nitric oxide synthase double-knockout mice. Circulation 2001;104:448-454.

[25] Cyrus T, Yao Y, Rokach J, Tang LX, Pratico D. Vitamin E reduces progression of atherosclerosis in low-density lipoprotein receptor-deficient mice with established vascular lesions. Circulation 2003;107:521-523.

[26] Lund EK, Gee JM, Brown JC, Wood PJ, Johnson IT. Effect of oat gum on the physical properties of the gastrointestinal contents and on the uptake of D-galactose and cholesterol by rat small intestine in vitro. Br J Nutr 1989;62:91-101.

[27] Theuwissen E, Mensink RP. Water-soluble dietary fibers and cardiovascular disease. Physiol Behav 2008;94:285-292.

[28] Lia A, Hallmans G, Sandberg AS, Sundberg B, Aman P, Andersson H. Oat betaglucan increases bile acid excretion and a fiber-rich barley fraction increases cholesterol excretion in ileostomy subjects. Am J Clin Nutr 1995;62:1245-1251.

[29] Zhang JX, Hallmans G, Andersson H, Bosaeus I, Aman P, Tidehag P, Stenling R, Lundin E, Dahlgren S. Effect of oat bran on plasma cholesterol and bile acid excretion in nine subjects with ileostomies. Am J Clin Nutr 1992;56:99-105.

[30] Kawakami A, Yoshida M. Remnant lipoproteins and atherogenesis. J Atheroscler Thromb 2005;12:73-76.

[31] Kypreos KE, Zannis VI. LDL receptor deficiency or apoE mutations prevent remnant clearance and induce hypertriglyceridemia in mice. J Lipid Res 2006;47:521-529. 


\section{Figure legends}

Fig. 1. Effect of Western diet \pm oat bran on plasma lipids and faecal cholesterol and bile acids. Total cholesterol vs. time after intake of $40 \%$ (A) or $27 \%$ (B) oat bran. The triglycerides (C) and relative amounts of LDL+VLDL (D) at baseline (striped bars) and at 16 weeks with $40 \%$ oat bran, or at 4 weeks with $27 \%$ oat bran $(n=19-20)$. The faecal cholesterol excretion $(\mathbf{E}, \mathrm{n}=6)$, and the faecal total bile acid excretion $(\mathbf{F}, \mathrm{n}=6)$ in mice fed $40 \%$ oat bran. ${ }^{*} \mathrm{P}<0.05,{ }^{* *} \mathrm{P}<0.01,{ }^{* * *} \mathrm{P}<0.001$ vs. control, and ${ }^{\#} \mathrm{P}<0.05,{ }^{\# \#} \mathrm{P}<0.01,{ }^{\# \#} \mathrm{P}<0.001$ vs. baseline.

Fig. 2. Effect of oat bran on plasma inflammatory markers in $\mathrm{LDLr}^{-/-}$mice. (A)-(C) Fibrinogen, SAA and IL-6 after intake of $40 \%$ oat bran for 16 weeks. (D) Soluble VCAM-1 after intake of 40 or $27 \%$ oat bran for 16 and 4 weeks, respectively $(\mathrm{n}=19-20)$. ${ }^{* * *} \mathrm{P}<0.001$, and $* \mathrm{P}<0.05$ vs. control, ns: not significant.

Fig. 3. Effect of oat bran on VCAM-1 and eNOS expression in the aortic root. (A) Representative images of VCAM-1 expression (red) and SYTOX ${ }^{\circledR}$ Green nuclear staining in cross sections of aortic root. Scale bar: $200 \mu \mathrm{m}$. (B) Summary of VCAM-1 expression in cross sections of aortic root $(\mathrm{n}=10)$. (C) Western blot analysis of eNOS expression. Upper panel: eNOS and lower panel: corresponding part of gel stained with Comassie Blue following transfer (loading control). (D) Summary of Western blot data $(\mathrm{n}=16-18) * * * \mathrm{P}<0.001$, $* * \mathrm{P}<0.01, * \mathrm{P}<0.05$ vs. control.

Fig. 4. Oat bran (40\%) reduces atherosclerotic lesion development. (A) Oil Red O stained en face preparations of aorta and quantitative data ( $\mathrm{n}=19-20$, lines show median values). Images shown are composites, see Supplementary data for details. (B) Aortic root cross sections stained with Oil Red $\mathrm{O}$ and quantitation of lesion size $(\mathrm{n}=7-9) . * \mathrm{P}<0.05, * * \mathrm{P}<0.01$ vs. control 


\section{TABLE}

Table 1. Initial body weight, body-weight gain, feed intake, caecal content and caecum wall weight in $\mathrm{LDLr}^{-/-}$mice fed control or 40 $\%$ oat bran Western diet after 16 weeks, and control or $27 \%$ oat bran Western diet after 4 weeks.

\begin{tabular}{|c|c|c|c|c|c|c|c|c|c|c|c|c|c|c|}
\hline & \multicolumn{3}{|c|}{ Control 16 weeks } & \multicolumn{4}{|c|}{ Oat bran $40 \% 16$ weesk } & \multicolumn{3}{|c|}{ Control 4 weeks } & \multicolumn{4}{|c|}{ Oat bran $27 \% 4$ weeks } \\
\hline & Mean & SEM & (n) & Mean & SEM & (n) & & Mean & SEM & (n) & Mean & SEM & (n) & \\
\hline Initial body weight (g) & 18.5 & 0.25 & (19) & 19.0 & 0.23 & (20) & ns & 20.1 & 0.44 & (20) & 20.3 & 0.48 & (20) & ns \\
\hline Body-weight gain (g) & 6.6 & 0.46 & (19) & 8.4 & 0.56 & $(20)$ & $P<0.05$ & 1.5 & 0.21 & (20) & 2.7 & 0.36 & (20) & $P<0.01$ \\
\hline Feed intake (g/mouse/ day) & 2.2 & 0.03 & (24) & 2.2 & 0.04 & (24) & ns & 2.4 & 0.06 & (7) & 2.3 & 0.07 & (8) & ns \\
\hline Caecal content (g) & 0.12 & 0.01 & (17) & 0.21 & 0.02 & $(17)$ & $P<0.001$ & 0.15 & 0.01 & (10) & 0.17 & 0.01 & (10) & ns \\
\hline Caecum wall weight (mg) & 53.9 & 2.8 & (19) & 69.2 & 3.1 & (20) & $P<0.001$ & 19.6 & 2.4 & (10) & 24.0 & 2.5 & (10) & ns \\
\hline
\end{tabular}

ns: not significant 
A

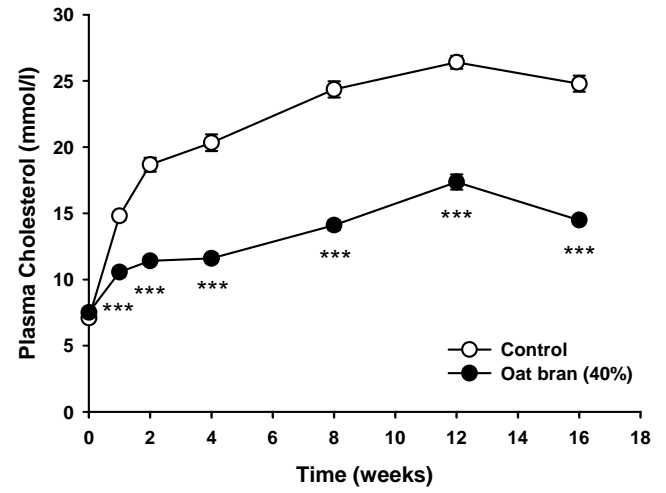

C

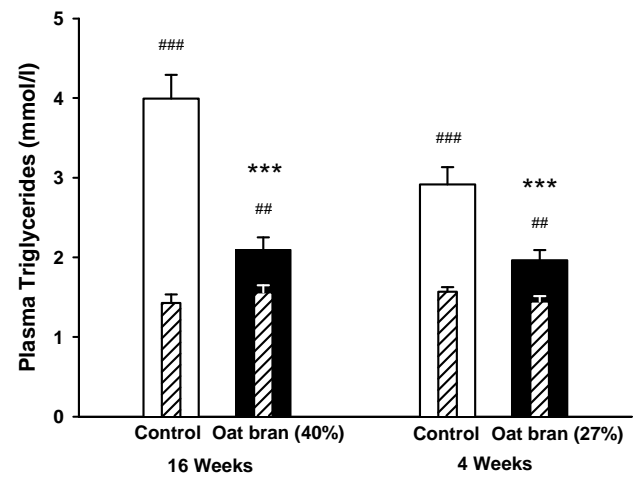

E

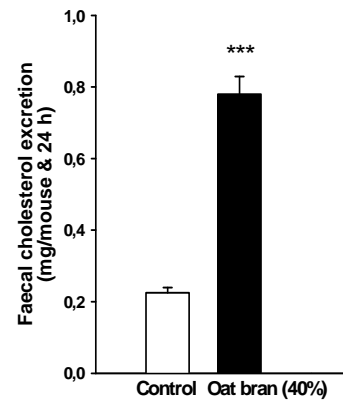

B

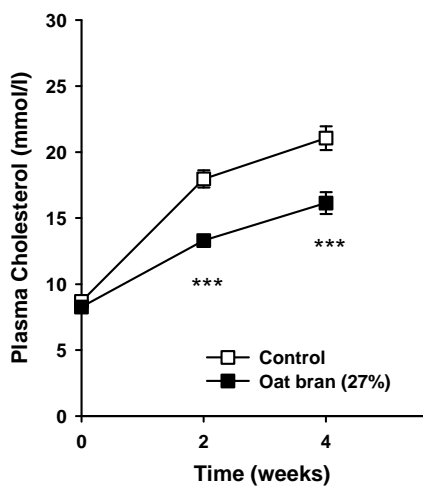

D

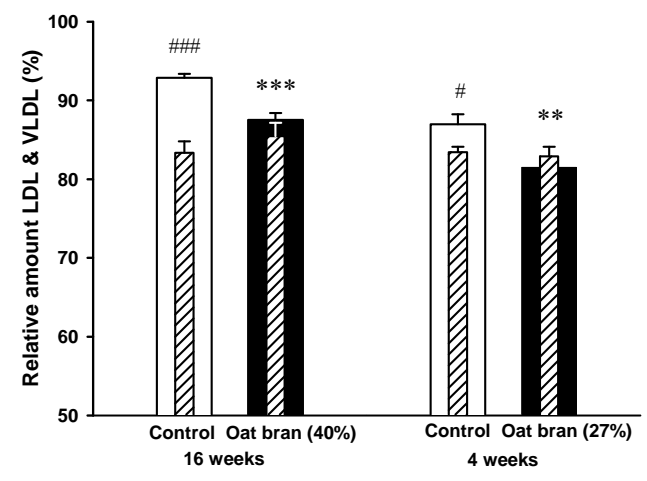

F

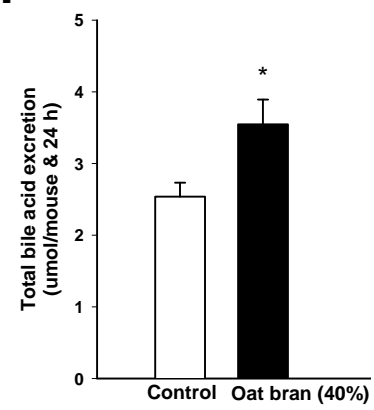

Figure 1. 

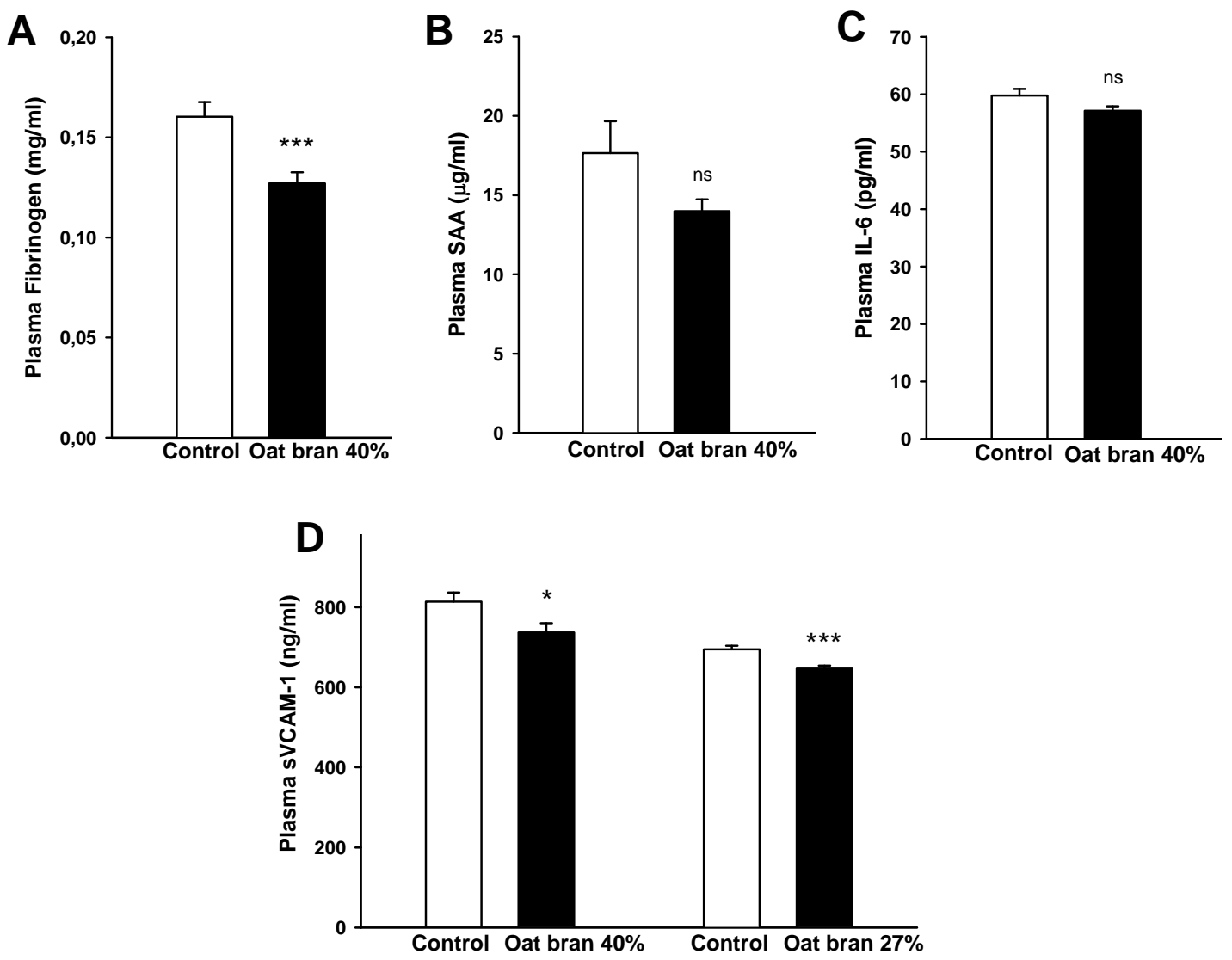

Figure 2 
A

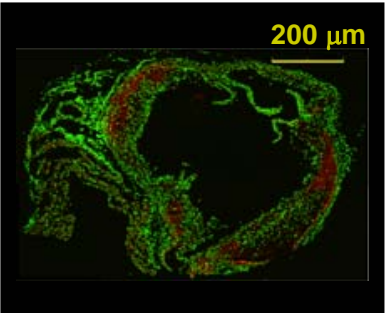

Control

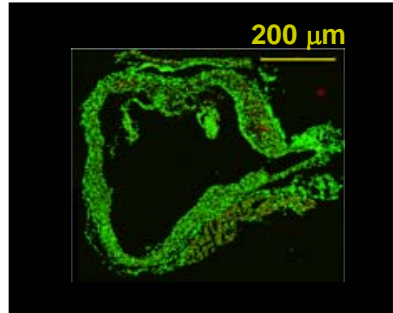

Oat bran (40 \%)
B

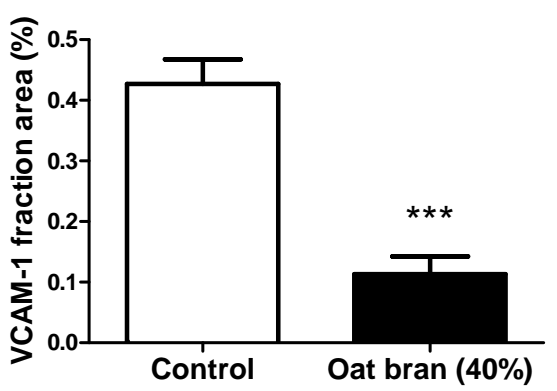

C

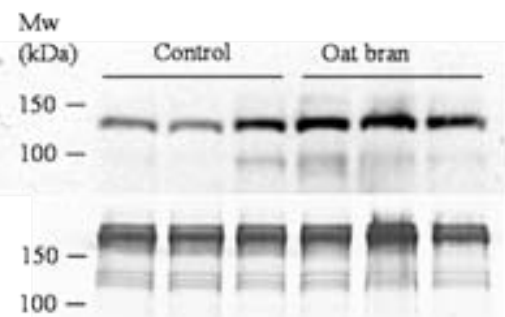

D

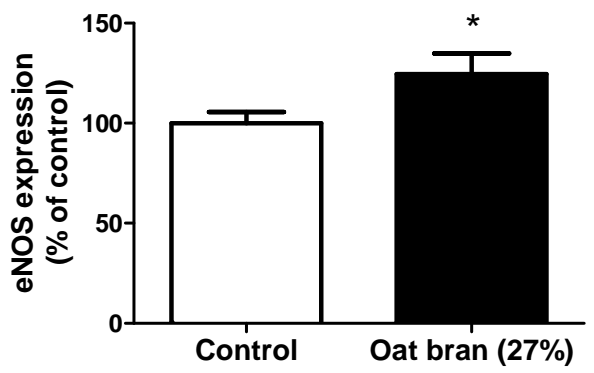

Figure 3. 


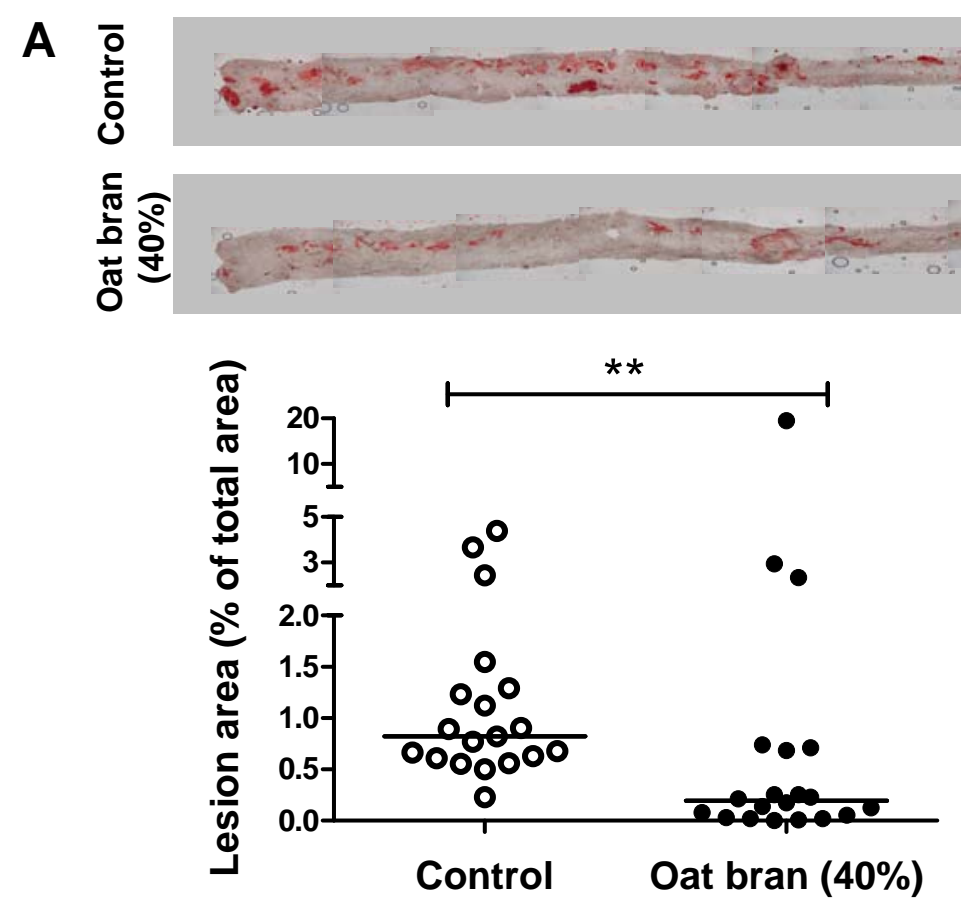

B
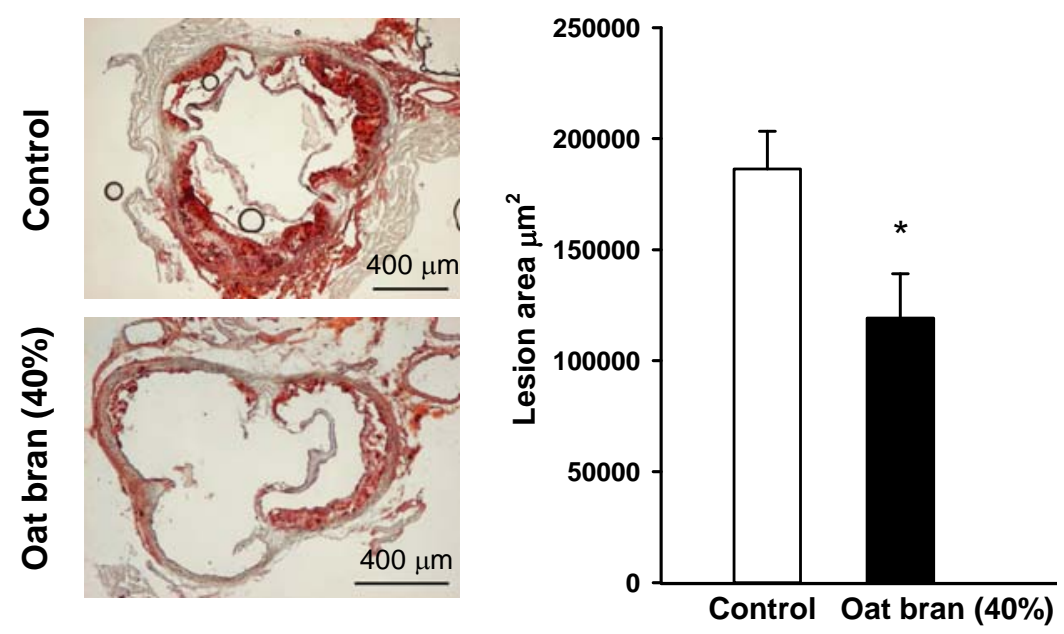

Figure 4. 


\title{
Oats (Avena sativa) reduce atherogenesis in LDL-receptor deficient mice.
}

\author{
Andersson $\mathrm{KE}^{1}$, Svedberg $\mathrm{KA}^{1}$, Lindholm $\mathrm{MW}^{2}$, Öste $\mathrm{R}^{3}$, Hellstrand $\mathrm{P}^{1}$ \\ ${ }^{1}$ Dept of Experimental Medical Science, ${ }^{2}$ Dept of Clinical Sciences, ${ }^{3}$ Dept of Food \\ Technology, Engineering and Nutrition, Lund University, Sweden
}

\section{Supplementary material}

\section{Materials and Methods}

Mice

Female LDL-receptor deficient homozygous $\left(\mathrm{LDLr}^{-/-}\right)$mice were purchased from Charles River laboratories (Sulzfeld, Germany). All experiments were approved by the Malmö/Lund regional ethical committee for laboratory animals (M86-05) and followed national guidelines for the care and use of animals. During an adaptation period of 2 weeks all mice were fed standard chow (R34, Lactamin, Sweden). At 8-10 weeks of age, the mice were randomly divided into two experimental groups, each containing 20 animals housed in cages of 10 mice. Blood samples were taken to establish baseline plasma parameter values. One group was fed Western diet supplemented with oat bran $(40 \%)$ and the other group control Western diet. The mice had free access to food and water throughout the experiment. They tolerated the studies well, but one mouse in the control group had to be sacrificed at week 12 and excluded from the study because of wounds on the hind leg. In an additional experiment we evaluated the effects on plasma cholesterol of a lower concentration of oat bran $(27 \%)$. Two groups of $20 \mathrm{LDLr}^{-/-}$mice each were fed Western diets for 4 weeks, with addition of $27 \%$ oat bran in the test diet. The aortas of these mice were used to determine the expression of eNOS in the aortic arch.

\section{Diets}

A Western diet was supplemented with $40 \%$ or $27 \%$ oat bran (wt/wt) at the expense of casein, corn starch, sucrose and butter (Table S1 and S2). In the control diets oat fibers were replaced by microcrystalline cellulose (Avicel ${ }^{\circledR}$ PH 101, FMC Biopolymer). Control and oat bran diets were formulated to keep fiber contents, energy and macronutrients equal, with 16 $\%$ protein, $42 \%$ carbohydrates, $42 \%$ fat (energy percent) and $0.05 \%$ cholesterol in both 
control and oat bran diets. Diet premixes were purchased from Research Diets Inc. (New Brunswick, NJ, USA), and melted anhydrous butter, maltodextrin, cellulose and oat bran were added in our laboratory by thorough mixing.

The oat bran used (Avena sativa cv. Sang, batch 1008596, Lantmännen AB, Järna, Sweden, pre-milled to a particle size less than $0.8 \mathrm{~mm}$ ) had a total fiber content of $16 \%$ (analyzed by Eurofins Food, Lidköping, Sweden), whereof $7.2 \%$ was beta-glucans, determined enzymatically (Megazyme International, Wicklow, Ireland). The diet with $40 \%$ oat bran thus contains approximately $3.0 \%$ beta-glucans and has a total fiber content of 6.5 $\%$, whereas the diet with $27 \%$ oat bran contains $2 \%$ beta-glucans and $4.4 \%$ total fiber. In the control diets oat fibers were replaced by $6.5 \%$ and $4.4 \%$ microcrystalline cellulose respectively. Feed consumption was determined per cage over 1-week periods and expressed as $g$ consumed per mouse per day.

\section{Tissue sampling}

Blood samples were drawn from vena saphena at baseline and at weeks 1, 2, 4, 8, 12 and 16. The samples were collected in EDTA-coated microvette tubes after $4 \mathrm{~h}$ fasting. Plasma was prepared by spinning whole blood at $5000 \mathrm{x}$ g for 10 minutes at $4{ }^{\circ} \mathrm{C}$ and stored at $-80^{\circ} \mathrm{C}$ until assayed. Plasma aliquots for lipoprotein analysis were supplemented with sucrose to a final concentration of $10 \%$ to protect the structure of the lipoproteins before freezing[1].

At week 16 all the faeces excreted during $24 \mathrm{~h}$ were collected from each cage (10 mice/cage). The faeces were lyophilized and weighed and then three parallel samples from each cage were analyzed for cholesterol content or total bile acids. For cholesterol measurements lipids were extracted from $0.1 \mathrm{~g}$ of minced faeces with $5 \mathrm{ml}$ hexane:isopropanol (3:2 + 0.005\% 2,6-Di-Tert-Butyl-4-Metylphenol), dried under nitrogen and reconstituted in isopropanol with $1 \%$ Triton X-100. This lipid extract was then analyzed with the same cholesterol reagents as the plasma samples. For bile acid measurements $0.25 \mathrm{~g}$ faeces were minced and extracted in $5 \mathrm{ml}$ of $75 \%$ ethanol at $50{ }^{\circ} \mathrm{C}$ for $2 \mathrm{~h}$ (as described in $\mathrm{Yu}$ et al.[2] After centrifugation the extract was diluted 1:10 in water before enzymatic determination in a 96-well format using the Diazyme Colorimetric Total Bile Acids Assay Kit according to the manufacturer's directions.

At the end of the study with $40 \%$ oat bran mice were anasthesized with rompun/ketalar and perfusion fixed with $15 \mathrm{ml}$ Histochoice tissue fixative (Amresco, Ohio, USA), injected into 
the left ventricle. The aorta was dissected free from connective and adipose tissue and cut open longitudinally from the iliac arteries to $1 \mathrm{~mm}$ below the left subclavian artery. It was then mounted en face on an ovalbumin-coated glass slide with the luminal side up[3]. After drying, the slide with the aorta was placed in Histochoice until staining. The aortic arch attached to the heart was placed and stored in Histochoice until embedded in OCT (Sakura Finetek, USA) and cryo-sectioned. The hearts were cut in $10 \mu \mathrm{m}$ sections using a cryomicrotome at $-22{ }^{\circ} \mathrm{C}$. Starting when all 3 aortic valve cusps were clearly visible in one section, five sections of the aortic root at $100 \mu \mathrm{m}$ intervals were collected from each mouse and the avarage of the lesion area was counted as $n=1$ in the statistical analysis. Cryo section collected like this were used for both immunfluorescence measurement of VCAM-1 and lesion analysis with Oil Red $\mathrm{O}$ and hematoxylin staining. The caecum with its contents was removed, emptied and weighed.

In the study with $27 \%$ oat bran the mice were sacrified by cervical dislocation, the aorta was removed, dissected free from connective tissue and kept frozen at $-80^{\circ} \mathrm{C}$ before Western blot analysis.

\section{Plasma lipids}

The total plasma cholesterol and triglyceride levels were determined by enzymatic analysis with Infinity cholesterol/triglycerides Liquid Stable reagent (Thermo Trace, Noble Park, Australia). Plasma lipoproteins were separated by electrophoresis in $0.8 \%$ agarose gels in barbital buffer[4] using a Sebia Hydragel 7 Lipoprotein(E), K20 chamber (Sebia, France). Apolipoprotein B-containing lipoproteins (LDL and very low density lipoprotein, VLDL) are separated from HDL by this method due to their individual charges. After Sudan black staining of the gels and densitometric scanning (BioRad GS 800 Calibrated Densitometer and Quantity One quantitation software) the relative amounts of HDL and VLDL+LDL were calculated from the intensity of the bands. Values of VLDL and LDL were summed since the bands are not always clearly distinguishable. This method yields relative amounts of lipoproteins in each sample. 


\section{Plasma inflammatory markers}

Commercially available murine ELISA kits were used for measuring plasma levels of inflammatory markers SAA (Tridelta Development Ltd, Ireland), fibrinogen (Immunology Consultants Laboratory, Inc. Newberg, USA) IL-6 and soluble VCAM-1 (sVCAM-1; R\&D Systems, Inc. Minneapolis, USA) in plasma collected after 16 weeks experimental food administration.

\section{Oil red $O$ staining}

The aortic en face preparations were stained with Oil Red $\mathrm{O}$ as described by Brånén et al[3] and covered with a coverslip. Fatty lesions were recognizable as dark, burgundy red objects, whereas adventitial fat stained much lighter red. Images of the en face preparations were captured at 20x magnification (7-8 images per aorta) and analyzed with Image ProPlus 4.5 Software (MediaCybernetics, Inc. Bethesda, MD, USA). The lesion size was expressed as lesion area in percent of total aortic surface area. The outline of the aortic surface and lesions were defined manually by a blinded observer. Pictures of aorta shown in Figure 3A are composites of 7-8 aligned, non-overlapping images.

Cryo sections of the aortic root from 10 randomly selected animals from each group were stained with Oil red $\mathrm{O}$ and counterstained with haematoxyline. The lesion size was quantified by computer-assisted morphometric analysis and expressed as mean lesion area per section.

\section{Analysis of VCAM-1 in aortic sections}

Cryo sections of the aortic root were incubated with primary rat-anti-mouse VCAM-1 antibodies (Chemicon) 1:200 in BSA and then with secondary Cy5 donkey-anti-rat antibodies (Santa Cruz) 1:500 in BSA. Counter staining for nuclei was done with SYTOX ${ }^{\circledR}$ Green (Molecular Probes, (Invitrogen) USA) 1:3000 in PBS. A Zeiss LSM 5 Pascal laser scanning confocal microscope was used to scan $1024 \times 1024$ px 8-bit image. Detector settings were fine calibrated for each glass slide and then kept constant per slide. All images were taken using a Plan-Neofluar 10x/0.3 lens using appropriate filter sets for Cy5 and SYTOX ${ }^{\circledR}$ Green emissions.

Image analysis was done using a custom-written program implemented in MATLAB ${ }^{\mathrm{TM}}$ $2007 \mathrm{~b}$ to quantitate the pixel area of $670 \mathrm{~nm}$-emitting (VCAM-1 stained) fluorescence relative 
to the total vessel wall area, which was obtained by supervised thresholding. Images were run through a $3 \times 3 \mathrm{px}, \sigma=5$ Gaussian filter to reduce effects of random noise. The weak autofluorescence signal detected in the 545-650 band was used to segment out tissue in the images by supervised thresholding and connected component analysis. Next, supervised thresholding was applied to generate a VCAM-1 only logic image. This image was subsequently multiplied by the tissue-segmented image. These final resultant images were used to obtain percentages of VCAM-1 signal found in the vessel wall.

\section{Western Blot eNOS}

In the additional experiment with $\mathrm{LDLr}^{-/-}$mice fed Western diet $\pm 27 \%$ oat bran for four weeks the aortic arch were dissected free from adventitial fat and homogenized in SDS sample buffer (62.5 mM Tris-HCl, 2\% SDS, 10\% glycerol, 5\% mercaptoethanol, 0,001\% bromphenolblue and protease inhibitor coctail (Sigma). The homogenates were boiled, centrifuged and protein concentrations were determined with EZQ protein determination (Molecular Probes). Proteins were separated with SDS-PAGE (10.5-14 \% gels) on a BioRad Criterion system loaded with $25 \mu \mathrm{g}$ protein in each lane and transferred to a nitrocellulose membrane. The membranes were incubated with an antibody against eNOS (BD Transduction Lab.), detected with chemiluminiscence (West Femto, Nordic Biolab) and analysed with Quantity One software (Biorad).

\section{Statistical Analysis}

Data are expressed as mean \pm SEM if not otherwise stated. Differences between oat bran and control were compared by one-tailed Student's t-test for unpaired data, while paired ttests were used for within-group changes from baseline. In lesion analysis of flat preparations data median values were analyzed with Mann-Whitney U-test. Values of $\mathrm{P}<0.05$ were considered statistically significant.

\section{References}

[1] Rumsey SC, Galeano NF, Arad Y, Deckelbaum RJ. Cryopreservation with sucrose maintains normal physical and biological properties of human plasma low density lipoproteins. J Lipid Res. 1992;33:1551-61. 
[2] Yu C, Wang F, Kan M, Jin C, Jones RB, Weinstein M, Deng CX, McKeehan WL. Elevated cholesterol metabolism and bile acid synthesis in mice lacking membrane tyrosine kinase receptor FGFR4. J Biol Chem. 2000;275:15482-9.

[3] Branen L, Pettersson L, Lindholm M, Zaina S. A procedure for obtaining whole mount mouse aortas that allows atherosclerotic lesions to be quantified. Histochem J. 2001;33:227-9.

[4] Noble RP. Electrophoretic separation of plasma lipoproteins in agarose gel. J Lipid Res. 1968;9:693-700. 
Table S1. Formulation of the Western diets and macronutrient contents

\begin{tabular}{|c|c|c|}
\hline Ingredient & $\begin{array}{l}\text { Control } \\
\text { g/kg diet }\end{array}$ & $\begin{array}{l}\text { Oat bran (40\%) } \\
\text { g/kg diet }\end{array}$ \\
\hline Casein, 80 Mesh $^{*}$ & 200 & 119 \\
\hline DL-Methionine $^{\dagger}$ & 3 & 5 \\
\hline Corn Starch & 265 & 53 \\
\hline Maltodextrin & 100 & 100 \\
\hline Sucrose & 100 & 91 \\
\hline Cellulose & 65 & 0 \\
\hline Butter, Anhydrous ${ }^{\ddagger}$ & 200 & 165 \\
\hline Corn Oil & 10 & 10 \\
\hline Mineral Mix S10026 & 10 & 10 \\
\hline DiCalcium Phosphate & 13 & 13 \\
\hline Calcium Carbonate & 5.5 & 5.5 \\
\hline Potassium Citrate, $1 \mathrm{H} 2 \mathrm{O}$ & 16.5 & 16.5 \\
\hline Vitamin Mix V10001 & 10 & 10 \\
\hline Choline Bitartrate & 2 & 2 \\
\hline Cholesterol $^{\ddagger}$ & 0 & 0.08 \\
\hline Oat $\mathrm{Bran}^{\S}$ & 0 & 400 \\
\hline Total & 1000 & 1000 \\
\hline$\underline{\text { Macronutrient contents } \|}$ & \% energy & \% energy \\
\hline Protein & 16 & 16 \\
\hline Carbohydrate & 42 & 42 \\
\hline Fat & 42 & 42 \\
\hline
\end{tabular}

${ }^{*}$ Casein is $88 \%$ protein.

${ }^{\dagger}$ Extra methionine was added to the oat diet since oat bran does not contain methionine.

${ }^{\ddagger}$ Anhydrous butter contains $230 \mathrm{mg}$ cholesterol/100 g. To compensate, extra cholesterol was added to the oat bran diet so that total amount of cholesterol was $0.46 \mathrm{~g} / \mathrm{kg}$ diet in both diets. $\S_{400} \mathrm{~g}$ oat bran contains $71 \mathrm{~g}$ protein, $206 \mathrm{~g}$ starch, $9 \mathrm{~g}$ sucrose, $65 \mathrm{~g}$ dietary fibre (whereof $29 \mathrm{~g} \beta$-glucans) and $14 \mathrm{~g}$ ash, as analyzed by Eurofins Food Lidköping, Sweden.

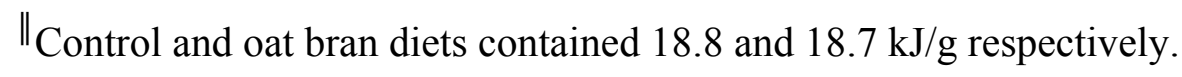


Table S2. Formulation of the Western diets and macronutrient contents

\begin{tabular}{|c|c|c|}
\hline Ingredient & $\begin{array}{l}\text { Control } \\
\text { g/kg diet }\end{array}$ & $\begin{array}{l}\text { Oat bran (27\%) } \\
\text { g/kg diet }\end{array}$ \\
\hline 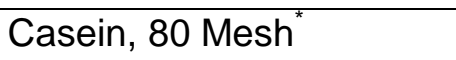 & 200 & 146 \\
\hline DL-Methionine $^{\dagger}$ & 3 & 4.5 \\
\hline Corn Starch & 281 & 142 \\
\hline Maltodextrin & 100 & 100 \\
\hline Sucrose & 100 & 94 \\
\hline Cellulose & 44 & 0 \\
\hline Butter, Anhydrous $^{\ddagger}$ & 200 & 176 \\
\hline Corn Oil & 10 & 10 \\
\hline Mineral Mix S10026 & 10 & 10 \\
\hline DiCalcium Phosphate & 13 & 13 \\
\hline Calcium Carbonate & 5.5 & 5.5 \\
\hline Potassium Citrate, $1 \mathrm{H} 2 \mathrm{O}$ & 16.5 & 16.5 \\
\hline Vitamin Mix V10001 & 10 & 10 \\
\hline Choline Bitartrate & 2 & 2 \\
\hline Cholesterol $^{\ddagger}$ & 0 & 0.06 \\
\hline Oat $\operatorname{Bran}^{\S}$ & 0 & 270 \\
\hline Total & 1000 & 1000 \\
\hline Macronutrient contents\| & \% energy & \% energy \\
\hline Protein & 16 & 16 \\
\hline Carbohydrate & 43 & 43 \\
\hline Fat & 41 & 41 \\
\hline
\end{tabular}

${ }^{\star}$ Casein is $88 \%$ protein.

${ }^{\dagger}$ Extra methionine was added to the oat diet since oat bran does not contain methionine.

${ }^{\ddagger}$ Anhydrous butter contains $230 \mathrm{mg}$ cholesterol/100 g. To compensate, extra cholesterol was added to the oat bran diet so that total amount of cholesterol was $0.46 \mathrm{~g} / \mathrm{kg}$ diet in both diets. $\S_{2} 270 \mathrm{~g}$ oat bran contains $48 \mathrm{~g}$ protein, $139 \mathrm{~g}$ starch, $6 \mathrm{~g}$ sucrose, $44 \mathrm{~g}$ dietary fibre (whereof $20 \mathrm{~g} \beta$-glucans) and $9 \mathrm{~g}$ ash, as analyzed by Eurofins Food Lidköping, Sweden.

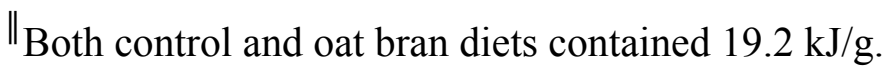

